\title{
ANALISIS KELAYAKAN FINANSIAL PENGEMBANGAN USAHATANI LABU MADU DI KABUPATEN PANDEGLANG PROVINSI BANTEN
}

\author{
Khaerul Saleh \\ Jurusan Agribisnis, Fakultas Pertanian, Universitas Sultan Ageng Tirtayasa Banten \\ Jl. Raya Jakarta KM 4 , Pakupatan Serang Banten, Indonesia \\ e-mail : khaerulsaleh63@yahoo.co.id
}

(Diterima 10 Juni 2020/Disetujui 3 Agustus 2020)

\begin{abstract}
Besides having a high economic value, Pumpkin honey also has good nutritional content, technically honey pumpkin cultivation is no different from other plants, but in pumpkin, honey cultivation requires a higher investment, especially at variable costs, this study was conducted in Pandeglang district, in general, it is suitable for pumpkin honey cultivation. The objectives of this study include to: (1) Financial feasibility of pumpkin honey farming. (2) The rate of sensitivity (sensitivity) to the decline in selling prices, increase in production costs and decrease in the amount of production (3) The feasibility of the aspects of cultivation, social environment, economics and marketing of Pumpkin Honey. tabulation and computational methods to facilitate analysis. Data analysis uses quantitative analysis and qualitative descriptive analysis. Quantitative analysis analyzes financial feasibility (B/C Ratio, NPV, IRR and PBP) and sensitivity analysis using applicable interest rates, qualitative descriptive analysis is used to determine the feasibility of cultivation, social environmental, economic and marketing aspects. The results showed that (1) Honey Pumpkin Cultivation in Cipeucang and Cimanuk Subdistricts of Pandeglang Regency was feasible to be cultivated with Gross B/C Ratio, Net B/C Ratio, NPV.IRR and Payback Period (PBP) feasible. (2) The possibility of a decrease in production, a decrease in output prices, and an increase in production costs, according to investment criteria and in a proper condition, and have a good level of sensitivity. (3) The technical aspects of cultivation from climate and rainfall following the Pumpkin Honey plant, the social and environmental aspects are feasible, the marketing aspects are feasible and very promising.
\end{abstract}

Keywords: financial feasibility, honey pumpkin farming, sensitivity analysis

\begin{abstract}
ABSTRAK
Selain memiliki nilai ekonomis yang tinggi, Labu madu juga memiliki kandungan gizi yang baik, secara teknis budidaya Labu madu tidak berbeda dengan tanaman lainnya akan tetapi dalam budidaya labu madu dibutuhkan investasi yang lebih tinggi terutama pada biaya variable, penelitian ini di lakukan di kabupaten Pandeglang yang secara umum sangat cocok untuk budidaya labu madu. Tujuan penelitian ini antara lain untuk mengetui: (1) Kelayakan finansial usahatani labu Madu. (2) Laju kepekaan (sensitivitas) terhadap penurunan harga jual, kenaikan biaya produksi dan penurunan jumlah produksi. (3) Kelayakan aspek budidaya, sosial lingkungan, ekonomi dan pemasaran Labu Madu. metode tabulasi dan komputasi untuk mempermudah analisis. Analisis data menggunakan analisis kuantitatif dan analisis deskriptif kualitatif. Analisis kuantitatif menganalisis kelayakan finansial (B/C Ratio, NPV, IRR dan PBP) dan analisis laju kepekaan dengan menggunakan suku bunga yang berlaku, Analisis deskriptif kualitatif digunakan untuk mengetahui kelayakan aspek budidaya, sosial lingkungan, ekonomi dan aspek pemasaran. Hasil penelitian menunjukkan bahwa (1) Budidaya tanaman Labu Madu di Kecamatan Cipeucang dan Cimanuk Kabupaten Pandeglang layak untuk diusahakan dengan nilai Gross B/C Ratio, Net B/C Ratio, NPV, IRR dan Payback Period (PBP) layak untuk dilakukan. (2) Kemungkinan penurunan produksi, penurunan harga output, dan kenaikan biaya produksi, sesuai dengan kriteria investasi dan dalam keadaan layak, dan memiliki tingkat sensitifitas yang baik. (3) Aspek teknis budidaya dari iklim dan curah hujan sesuai dengan tanaman Labu Madu, aspek sosial lingkungan dan ekonomi sudah layak, aspek pemasaran layak dan sangat menjanjikan.
\end{abstract}

Kata kunci: analisis sensitivitas, kelayakan finansial, usahatani labu madu 


\section{PENDAHULUAN}

Provinsi Banten merupakan salah satu provinsi yang memiliki potensi besar dalam bidang pertanian. Sektor pertanian merupakan subsektor yang menyumbang Pendapatan Domestik Regional Bruto (PDRB) yang tinggi dibanding sektor lainnya yaitu sebesar 32,6 persen (BPS Provinsi Banten, 2014). Salah satu kabupaten di Provinsi Banten yang memiliki peran strategis di sektor pertanian adalah Kabupaten Pandeglang, dimana Kabupaten Pandeglang pada tahun 2017 mampu menyumbangkan PDRB dari sektor pertanian yakni sebesar 22,6 persen. Sektor pertanian, terutama subsektor hortikultura dalam menyumbang PDRB berada pada urutan kedua setelah sector kahutanan (BPS Pandeglang 2017) dan menempati urutan terbesar ketiga di Provinsi Banten pada tahun 2016 (BPS Provinsi Banten 2017). Hal ini mengindikasi bahwa komoditas hortikultura khususnya Labu Madu di Kabupaten Pandeglang mempunyai prospek yang lebih baik untuk dikembangkan lebih lanjut. Sumberdaya alam yang dimiliki Kabupaten Pandeglang cukup berpotensial, dan sangat cocok untuk pengembangan komoditas hortikultura khususnya buah Labu Madu, dan diharapkan di masa yang akan datang Kabupaten Pandeglang menjadi sentra buah Labu Madu.

Pemerintah Kabupaten Pandeglang dengan program unggulan subsektor hortikultura khususnya buah (durian, manggis, rambutan serta Labu Madu) mampu meningkatkan kesejahteraan dan pendapatan masyarakat.

Labu Madu mulai dibudidayakan di Pandeglang sejak tahun 2010, jumlah permintaan akan Labu Madu setiap tahun mengalami peningkatan selain sebagai kegiatan usahatani, tanaman labu madu juga dijadikan sebagai obyek Agrowisata Labu Madu yang aktifitasnya cukup berkembang. Data Dinas Pertanian Tanaman Pangan dan Hortikultura Kab. Pandeglang (2018) saat ini Labu Madu dikembangkan hingga di beberapa kecamatan, yang awalnya di Kecamatan Cipeu- cang sekarang sudah meliputi Kecamatan Cimanuk, Menes, Mandalawangi, Majasari dan Kecamatan Pandeglang. Selain permintaan yang terus meningkat terhadap buah Labu Madu, budidaya tanaman Labu madu relatif mudah dilakukan serta memiliki bentuk buah yang unik sehingga banyak orang tertarik sekedar untuk menikmati keindahannya (Pandeglang, Redaksi 24.com 2019).

Labu madu/butternut squash (Cucurbita moschata Durch) memiliki banyak kandungan karbohidrat juga kaya serat, vitamin A, C dan E dan mineral, yang mampu membantu meningkatkan kekebalan tubuh dan melawan radikal bebas. Warna oranye pada labu madu mengandung beta-karoten tinggi, sebuah antioksidan yang mengubah vitamin $\mathrm{A}$ dan membantu mengurangi risiko kanker. Labu madu juga mengandung B-Kompleks vitamin seperti folat, niacin, vitamin B-6 (pyridoxine), thiamin, dan asam pantotenat, dan mineral seperti tembaga, kalsium, besi dan fosfor (Logistik BPPI, 2016).

Berdasarkan uraian dan perumusan masalah maka dari penelitian ini dapat ditentukan tujuan penelitiannya ialah (1) mengetahui kelayakan finansial usahatani Labu Madu, (2) mengetahui tingkat sensitifitas terhadap penurunan harga jual, kenaikan biaya pro-duksi, penurunan jumlah produksi. (3) mengetahui kelayakan aspek budidaya, sosial lingkungan, ekonomi dan pemasaran.

\section{METODE}

Metode penelitian yang digunakan adalah metode survei pengambilan sempel dilakukan random dengan mendata semua petani Labu madu di dua kecamatan. Lokasi Penelitian adalah Kecamatan Cipeucang dan Cimanuk. Lokasi penelitian ditentukan secara sengaja (purposive) dengan pertimbangan bahwa di lokasi tersebut merupakan salah satu sentra produksi Labu Madu di Kabupaten Pandeglang.

Adapun jumlah sampel yang diambil dalam penelitian ini adalah petani rakyat yang terdapat di Kecamatan Cipeucang 20 
petani dan Cimanuk 10 petani sehingga jumlah responden sebanyak 30 petani. Dan merupakan merupakan penelitian populasi. (Arikunto 2002)

Data primer diperoleh melalui wawancara secara langsung dengan petani. Data sekunder diperoleh dari studi literatur, laporanlaporan, publikasi artikel dan pustaka lainnya yang berhubungan dengan penelitian ini serta lembaga atau instansi terkait. Metode yang digunakan untuk analisis data adalah metode tabulasi dan komputasi.

Data yang diperoleh diolah secara komputasi dan dianalisis secara kuantitatif dan deskriptif kualitatif. Analisis kuantitatif digunakan untuk mengkaji aspek finansial dan sensitivitas, sedangkan analisis deskriptif kualitatif digunakan untuk mengetahui beberapa aspek yang berperan dalam usahatani Labu Madu, yaitu aspek budidaya, ekonomi, sosial lingkungan dan pemasaran.

Kajian mengenai analisis kelayakan finansial relatif sudah banyak mendapatkan perhatian dari para akademisi (Kusuma, 2010; Sutojo dkk. 2000; Kadariah 2001; Rizana 2014; Seftiana 2010), untuk analisis di berbagai bidang industri. Selain itu, analisis kelayakan finansial juga dilakukan oleh para pelaku di bidang industri manufaktur (Firmansyah, 2006; Wolf, 2005; Mc. Keough, 2005) dan termasuk juga pada industri berbasis agro atau pertanian (Erlina, 2006; Rantala dkk., 2009).

\section{PENGOLAHAN DATA}

Tahapan dalam melakukan analisa kelayakan finansial usahatani Labu madu adalah:

1. Biaya investasi

2. Biaya produksi

3. Estimasi Penjualan

4. Estimasi Biaya Produksi

5. Cash Flow

6. Pemenuhan kriteria kelayakan finansial : Analisa Break Even Point (BEP), Net Present Value (NPV), Incremental Rate of Return (IRR), Net Benefit Cost Ratio (Rasio B/C) dan Pay Back Period (PBP)

7. Analisis sensitivitas
Data diolah dalam bentuk tabulasi, kemudian dianalisis secara matematis dengan merujuk pada aspek-aspek perhitungan analisis kelayakan finansial, yaitu Break Even Point (BEP), Net Present Value (NPV), Payback Period (PBP), Incremental Rate of Return (IRR), dan Rasio B/C (Kusuma dkk., 2012).

Data biaya variabel dan biaya tetap digunakan untuk mengetahui total biaya produksi atau total cost, dengan perhitungan:

$\mathrm{TC}=\mathrm{VC}+\mathrm{FC}$

Dimana :

$\mathrm{TC}=$ Total Cost

$\mathrm{VC}=$ Variabel Cost

$\mathrm{FC}=$ Fixed Cost

Penetapan asumsi dilakukan untuk membantu pengolahan data, penetapan Harga Pokok Produksi (HPP) dan pembuatan cashflow. Asumsi yang ditetapkan meliputi jumlah hari kerja karyawan, harga jual produk, penurunan kapasitas produksi yang diharapkan, dan peningkatan harga Sarana Produksi (Idham, 2010; Kusumanto, 2008)

Perhitungan biaya yang dilakukan meliputi biaya investasi, biaya variabel-semi variabel, biaya tetap, dan biaya lainnya. Biaya investasi adalah sejumlah modal atau biaya yang digunakan untuk memulai usaha atau mengembangkan usaha (Pujawan, 2004). Biaya variabel merupakan biaya yang rutin dikeluarkan setiap kegiatan produksi dimana besarnya tergantung pada jumlah produk yang ingin diproduksi (Ardana, 2008). Biaya tetap adalah jenis biaya yang lain yang rutin dikeluarkan oleh petani selama kegiatan usahatani berlangsung, akan tetapi besarnya biaya tetap tidak tergantung pada kapasitas produksi.

Kriteria investasi yang digunakan dalam analisis kelayakan finansial antara lain (Idham, 2010; De Gamo, 1984; Blank, 2002; Pujawan, 2004 Kadariah 2001; Rizana 2014; Seftiana 2010):

BEP adalah suatu titik jumlah produksi atau penjualan yang harus dilakukan agar biaya yang dikeluarkan dapat tertutupi kem- 
bali atau nilai dimana profit yang diterima usahatani adalah nol.

$B E P$ unit $=\frac{F C}{P-V C}$ atau $B E P$ Rupiah $=\frac{F C}{1-V C / P} \ldots$

Dimana :

$\mathrm{FC}=$ Biaya Tetap

$\mathrm{P}=$ Harga Jual per unit

$\mathrm{VC}=$ Biaya Variabel per unit

Analisis Net Present Value dilakukan untuk melihat bagaimana nilai investasi dengan mempertimbangkan perubahan nilai mata uang. NPV merupakan perbedaan antara nilai sekarang dari keuntungan dan biaya (Sudong, 2002).

$N P V=\sum_{t=1}^{n} \frac{(b t-C t}{(1+i)^{t}}$

Dimana :

$\mathrm{Bt}=$ Penerimaan kotor tahun ke- $\mathrm{t}$

$\mathrm{N}=$ Umur ekonomi

$\mathrm{Ct}=$ Biaya kotor tahun ke- $\mathrm{t}$

$\mathrm{I}$ = tingkat suku bunga

Kriteria yang digunakan (Diatin, 2007) :

$\mathrm{NPV}>0$, usaha layak untuk dijalankan

$\mathrm{NPV}=0$, usaha tersebut mengembalikan sama besarnya nilai uang yang ditanamkan

NPV $<0$, usaha tidak layak untuk dijalankan

IRR tingkat investasi adalah tingkat suku bunga yang berlaku (discount rate) yang menunjukkan nilai sekarang (NPV) sama dengan jumlah keseluruhan investasi proyek atau dengan kata lain tingkat suku bunga yang menghasilkan NPV sama dengan nol. IRR dihitung dengan menggunakan rumus (Kadariah. 2001; Kusumanto, 2008; Astanu, 2013).

$I R R=i+\left(\frac{N P V^{+}}{N P V^{+}-N P V}\right) i-i^{-}$

Dimana :

IRR = Internal Rate of Return,

$\mathrm{NPV}^{+}=\mathrm{NPV}$ positif,

$\mathrm{NPV}=\mathrm{NPV}$ negatif,

i+ $\quad=$ tingkat suku bunga pada NPV positif

$\mathrm{i} \quad=$ tingkat suku bunga pada NPV negatif
Kriteria pengambilan keputusan ialah jika IRR > tingkat suku bunga, maka usahatani Labu Madu layak untuk diusahakan, jika IRR = tingkat suku bunga, maka usahatani Labu Madu dalam keadaan impas dan jika IRR < tingkat suku bunga, maka usahatani Labu Madu tidak layak untuk diusahakan.

Estimasi jangka waktu pengembalian investasi suatu proyek dapat ditunjukkan dengan perhitungan Payback Period (Fazwa dkk., 2001). Payback periode adalah waktu minimum untuk mengembalikan investasi awal dalam bentuk aliran kas yang didasarkan atas total penerimaan dikurangi semua biaya (Erlina, 2006; Astanu,2002; Diatin. 2007). Payback Period mengetahui periode waktu yang diperlukan untuk pembayaran kembali seluruh pengeluaran investasi, yang menggunakan rumus Kadariah (2001).

$P B P=\frac{\text { Investasi Awal }}{\text { AbPenerimaan Periode }} X 1$ Tahun

Suatu usaha dikatakan layak jika nilai payback period lebih kecil atau sama dibandingkan umur investasi usaha. Perhitungan rasio $\mathrm{B} / \mathrm{C}$ merupakan perbandingan antara penerimaan total dan biaya total, yang menunjukkan nilai penerimaan yang diperoleh dari setiap rupiah yang dikeluarkan. Proyek dinyatakan layak apabila rasio $\mathrm{B} / \mathrm{C} \geq 1$ (Surahman dkk, 2007; Kadariah 2001). Penenetuan Ratio BC dapat dilakukan dengan dua kriteri yaitu;

a. Net Benefit-Cost Ratio (Net B/C)

$N e t B / C=\frac{\sum B t-C t(1-\mathrm{i})^{t}}{\sum C t-B t(1-\mathrm{i})^{t}}$

Dimana :

Net $B / C=$ Net Benefit Cost Ratio,

Bt = Benefit (penerimaan/batang),

$\mathrm{Ct}=$ Cost (biaya) pada tahun $\mathrm{t}$,

i = tingkat suku bunga(14\%),

$\mathrm{n}=$ umur ekonomis peralatan

$\mathrm{t}=\operatorname{tahun}(3$ tahun). 
b. Gross Benefit-Cost Ratio (Gross B/C Ratio)

$$
\operatorname{ross} \quad \mathrm{B} / \mathrm{C}=\frac{\sum_{t=1}^{n}\left(\frac{B t}{(1+i)^{t}}\right)}{\sum_{t=1}^{n}\left(\frac{C t}{(1+i)^{t}}\right)} \ldots \ldots \ldots(7)
$$

\section{Dimana :}

Gross B $/ C=$ Gross Benefit Cost Ratio,

$\mathrm{Bt} \quad=$ Benefit tahun (t: $1,2,3 \ldots \mathrm{n})$

$\mathrm{Ct}=$ Cost pada tahun $\mathrm{t}$,

i $=$ tingkat suku bunga (14\%).

Analisis sensitivitas dilakukan dengan memperhitungkan salah satu kemungkinan seperti penurunan produksi, penurunan harga jual dan peningkatan biaya produksi. Usahatani Labu Madu di Kecamatan Cipeucang dan Cimanuk mengalami penurunan harga jual $12,5 \%$, kenaikan biaya produksi $6,41 \%$ dan penurunan jumlah produksi $10 \%$. Sensitivitas dapat dihitung menggunakan rumus Gittinger dan Hans Adler (1993).

Laju Kepekaan $=\frac{\left|\frac{X_{i-X_{0}}}{\bar{X}}\right| x_{100 \%}}{\left|\frac{Y_{i-Y_{0}}}{\bar{Y}}\right| x_{100 \%}} \ldots .$. (8)

Dimana :

$\mathrm{X} 1=\mathrm{NPV}$ atau IRR atau Net $\mathrm{B} / \mathrm{C}$ ratio atau Gross B/C atau PBP setelah terjadi perubahan,

$\mathrm{X} 0=\mathrm{NPV}$ atau IRR atau Net $\mathrm{B} / \mathrm{C}$ ratio atau Gross B/C atau PBP sebelum terjadi perubahan,

$\ddot{X}=$ Rata-rata perubahan NPV atau IRR atau Net B/C ratio atau Gross B/C atau PBP,

$Y 1=$ Harga jual atau biaya produksi atau produksi setelah terjadi perubahan,

$Y 0=$ Harga jual atau biaya produksi atau produksi sebelum terjadi perubaha dan

$\tilde{Y}$ = Rata-rata perubahan harga jual atau biaya produksi atau produksi.

Kriteria laju kepekaan ialah jika nilai laju kepekaan > 1, maka hasil kegiatan usaha sensitif terhadap perubahan dan jika nilai laju kepekaan $<1$, maka hasil kegiatan usaha tidak sensitif terhadap perubahan Metode analisis deskriptif kualitatif digunakan untuk menganalisis kelayakan aspek budidaya, ekonomi, sosial dan lingkungan serta pemasaran dari budidaya Labu Madu.

\section{HASIL DAN PEMBAHASAN}

\section{KARAKTERISTIK RESPONDEN}

Petani responden berumur 20 - 55 tahun, dengan rata-rata 45,5 tahun. Tingkat pendidikan petani adalah Tingkat Sarjana (S1) sebanyak 3 orang (10\%), Tamat Sekolah Menengah Atas (SMA) sebanyak 21 orang (70\%), Sekolah Menengah Pertama (SMP) sebanyak 4 Orang $(13,3 \%)$ dan Sekolah Dasar sebanyak 2 orang $(6.6 \%)$. Luas lahan usahatani Labu Madu antara 0,1 hektare hingga 0,25 hektare dengan rata-rata 0,16 hektare. Produksi Labu Madu yang dihasilkan adalah sebesar 3,0 kg hingga 4,5 kg per batang dengan harga jual Labu Madu Rp 12.000/kg sehingga penerimaan rata-rata petani per musim Tanam sebesar Rp 19.807.000. Benih Labu Madu yang dibudidayakan sudah berbentuk bibit (kecambah) dengan harga $\mathrm{Rp}$ 1.400 perbatang, pupuk yang digunakan selain pupuk organik juga menggunakan pupuk kimia seperti NPK, SP36, Urea, KNO3, Gandhasil, dan Power Nutrition. Pestisida yang digunakan juga pestisida kimia baik yang padat maupun yang cair. Satu botol pestisida berisikan $250 \mathrm{ml}$. Peralatan yang digunakan ialah peralatan sederhana seperti cangkul, arit, golok, ember, hand sprayer, bambu dan plastik mulsa dengan umur teknis rata-rata 3 tahun.

\section{ANALISIS FINANSIAL USAHATANI LABU MADU}

Tabel 1. Struktur Penggunaan Biaya dan Penerimaan Usahatani Labu Madu per $0,5 \mathrm{Ha}$

\begin{tabular}{clr}
\hline No & $\begin{array}{c}\text { Jenis Kelompok } \\
\text { Biaya }\end{array}$ & \multicolumn{1}{c}{ Jumlah } \\
\hline 1 & Biaya Tetap & 19.652 .500 .00 \\
2 & Biaya Variabel & 48.524 .375 .00 \\
3 & Depresiasi & 4.911 .250 .00 \\
4 & Penerimaan & 99.038 .504 .00 \\
\hline
\end{tabular}


Tabel 2. Kriteria Finansial Usahatani Labu Madu di Kabupaten Pandeglang

\begin{tabular}{lcc}
\hline \multicolumn{1}{c}{ Kriteria } & Nilai & Keterangan \\
\hline Net B/C & 1,42 & Layak \\
Gross B/C & 3.53 & Layak \\
PBP (tahun) & 0,59 & Layak \\
NPV (Rp) & Rp 44.658.301,28 & Layak \\
IRR (\%) & $27.24 \%$ & Layak \\
\hline Sumber : Data Primer Diolah, 2020 & \\
\hline
\end{tabular}

Tabel 1 dan 2, menunjukkan secara ekonomis usatani Labu madu sangat menguntungkan, ada tiga variabel biaya yang relatif besar yaitu biaya bibit, mulsa, tenaga kerja dan bambu. Secara ekonomi sebagaimana Tabel 2 terlihat bahwa dimana Ratio BC PBP, NVP dan IRR dikatakan layak untuk diusahakan

\section{ANALISIS SENSITIVITAS (SWITCHING VALUE) DAN KELAYAKAN USAHATANI LABU MADU}

Analisis sensitivitas (switching value) pada budidaya Labu Madu adalah dengan melakukan 3 (tiga) skenario, skenario pertama diasumsikan produksi menurun sebesar $10 \%$ akibat adanya perubahan iklim yang ekstrim dan serangan hama penyakit, skenario ke 2 diasumsikan bahwa dengan semakin banyaknya petani yang membudidayakan labu madu maka jumlah barang yang ditawarkan meningkat berakibat pada harga produk mengalami penurunan sebesar $12,5 \%$ dari harga pasar, dan skenario ke 3 akibat adanya inflasi maka biaya operasional (sarana produksi) mengalami kenaikan sebesar 6,5\%.

Pada skenario 1 sebagaimana Tabel 3, yakni produksi diasumsikan menurun se- besar $10 \%$ yang didapatkan dari informasi petani dan Dinas Tanaman Pangan dan Hortikultura Pandeglang akibat serangan hama dan penyakit dan perubahan iklim.

Tabel 3 dapat dilihat bahwa penurunan produksi Labu Madu sebesar 10\% mengalami perubahan dari masing-masing kriteria investasi, Net B/C sensitif terhadap perubahan akan tetapi nilai Gross B/C, , NPV, IRR dan Payback Period masih dalam keadaan layak. Setelah dianalisis semua kriteria investasi seperti Gross B/C, Net B/C, NPV, Payback Period dan IRR menunjukkan sensitif terhadap perubahan akibat adanya penurunan produksi. Hal ini disebabkan karena tanaman Labu Madu secara umum masih belum banyak dikenal oleh masyarakat luas pada hal dari beberapa penelitian buah Labu Madu memiliki kalori yang sangat tinggi dan rendah kadar gula sehingga sangat cocok untuk penderita diabetes (namun perlu ada penelitian lebih lanjut)

Skenario usahatani dilakukan melalui tiga asumsi yaitu kenaikan harga input, penurunan produksi dan penurunan harga. Secara ekonomi usahatani labu madu sangat layak diusahakan karena selain memberikan nilai keuntungan yang tinggi juga tidak rentang terhadap perubahan baik harga biaya maupun produksi sebagaimana terlihat pada Tabel 3, Tabel 4 dan Tabel 5.

Kelayakan usahatani Labu Madu yang dilakukan petani di Kecamatan Cipeucang dan Cimanuk Kabupaten Pandeglang setelah dianalisis lebih lanjut baik ekonomi maupun teknis Budidaya, budidaya Labu Madu sangat cocok dengan kondisi geografis, suhu dan iklim wilayah setempat yakni antara $25-30^{\circ} \mathrm{C}$ dengan curah hujan 1000-2000 mm/tahun,

Tabel 3. Perubahan Nilai Analisis Usaha Akibat Adanya Penurunan Produksi Sebesar 10\%

\begin{tabular}{lcccc}
\hline \multicolumn{1}{c}{ Kriteria } & Nilai Awal & Nilai Perubahan & $\begin{array}{c}\text { Laju } \\
\text { Kepekatan }\end{array}$ & Keterangan \\
\hline Net B/C & 1,42 & 1,86 & 7,10 & Sensitif \\
Gross B/C & 3.53 & 4,93 & 8.82 & Sensitif \\
PBP (tahun) & 0,59 & 0,45 & 10.70 & Sensitif \\
NPV (Rp) & Rp $44.658 .301,28$ & Rp $41.513 .829,79$ & 1,9 & Sensitif \\
IRR (\%) & $27.24 \%$ & $29,98 \%$ & 2,51 & Sensitif \\
\hline Sur
\end{tabular}


Tabel 4. Perubahan Nilai Analisis Usaha Akibat Adanya Penurunan Harga Output Sebesar $12,5 \%$

\begin{tabular}{lcccc}
\hline \multicolumn{1}{c}{ Kriteria } & Nilai Awal & Nilai Perubahan & $\begin{array}{c}\text { Laju } \\
\text { Kepekatan }\end{array}$ & Keterangan \\
\hline Net B/C & 1,42 & 1,48 & 2,96 & Sensitif \\
Gross B/C & 3.53 & 3,75 & 1,82 & Sensitif \\
PBP (tahun) & 0,59 & 0,63 & 2,49 & Sensitif \\
NPV (Rp) & Rp 44.658.301,28 & Rp 43.604.700,17 & 1,00 & Sensitif \\
IRR (\%) & $27.24 \%$ & $27,62 \%$ & 1,10 & Sensitif \\
\hline
\end{tabular}

Sumber : Data Primer Diolah, 2020

Tabel 5. Perubahan Nilai Analisis Usaha Akibat Adanya Kenaikan Biaya Opeasional Sebesar $6,5 \%$

\begin{tabular}{lcccc}
\hline \multicolumn{1}{c}{ Kriteria } & Nilai Awal & Nilai Perubahan & $\begin{array}{c}\text { Laju } \\
\text { Kepekatan }\end{array}$ & Keterangan \\
\hline Net B/C & 1,42 & 1,57 & 2,96 & Sensitif \\
Gross B/C & 3.53 & 4,01 & 1,82 & Sensitif \\
PBP (tahun) & 0,59 & 0,54 & 2,49 & Sensitif \\
NPV (Rp) & Rp $44.658 .301,28$ & Rp. $46.164 .184,26$ & 1,17 & Sensitif \\
IRR (\%) & $27.24 \%$ & $28,16 \%$ & 1,01 & Sensitif \\
\hline
\end{tabular}

Sumber : Data Primer Diolah, 2020

dengan $\mathrm{pH}$ yang netral sehingga terhindar dari Busuk akar dan daun. Kondisi tanah sedikit berpasir dengan ketinggian tanah dibawah 500m dpl (Amir Hamzah, 2014). Daerah penelitian Labu Madu di Kecamatan Cipeucang dan Cimanuk sudah memenuhi kriteria syarat tumbuh Labu Madu.

Labu Madu tidak memerlukan teknis khusus dalam perawatannya. Cara penggunaan pupuk dan dosis obat-obatan sudah sesuai dengan yang dianjurkan. Sumber sarana produksi seperti benih, bibit, obat-obatan tidak sulit didapatkan oleh petani. Petani di daerah penelitian umumnya tergabung dalam kelompok tani sehingga mempermudah dalam memenuhi kebutuhan sarana produksi terutama dalam memenuhi kebutuahn Pupuk kimia.

Data menunjukkan bahwa hanya 35\% petani di Kecamatan Cipeucang dan Cimanuk menyatakan kesulitan dalam mendapatkan pupuk kimia, sedangkan $65 \%$ petani menyatakan mudah dalam mendapatkan pupuk, karena petani tersebut selain tergabung dalam kelompok tani pupuk kimia mudah diperoleh dikios -kios tani.

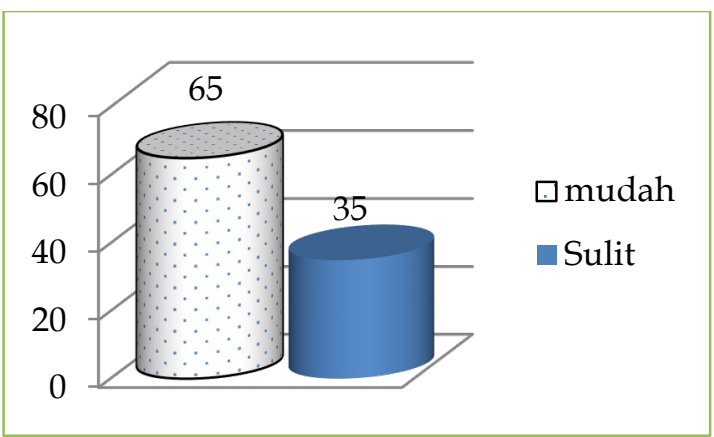

\section{Gambar 1. Kesulitan Petani dalam Mendapatkan Pupuk Kimia \\ Sumber : Hasil Olahan Data Primer, 2020}

\section{KELAYAKAN EKONOMI}

Secara aspek ekonomi dan setelah dihitung secara finansial budidaya Labu Madu layak untuk dibudidayakan. Sebagian besar petani yang membudidayakan Labu Madu dapat meningkatkan pendapatan dalam memenuhi kebutuhan hidupnya.

Kendala yang umumnya dirasakan petani ialah keterbatasan modal untuk pembelian sarana produksi sehingga berakibat pada petani membudidayakannya Labu Madu secara terbatas. Untuk mengatasi kebutuhan modal sebagain besar petani menyisihkan sebagian keuntungan untuk keberlanjutan usahataninya. Umumnya Petani labu 
Madu di Kecamatan Cipeucang dan Cimanuk tidak memiliki pekerjaan tetap (buruh), beberapa petani memiliki pekerjaan tetap seperti PNS dan karyawan sehingga kebutuhan modal dapat dipenuhi melalui proses meminjam modal melalui koperasi ditempat mereka bekerja. Gambar 2 menjelaskan bahwasanya $50 \%$ petani memakai modal sendiri, 35\% menggunakan modal pinjaman kelompok sedangkan $15 \%$ mendapatkan pinjaman dari pihak lain. Pengembalian modal dari kelompok dilakukan saat panen dengan jasa sebesar $2,5 \%$, sedangkan dari pihak lain dilakukan pembayaran sama dengan pinjaman dari kelompok namun jasa yang dibebankan sebesar $10 \%$.

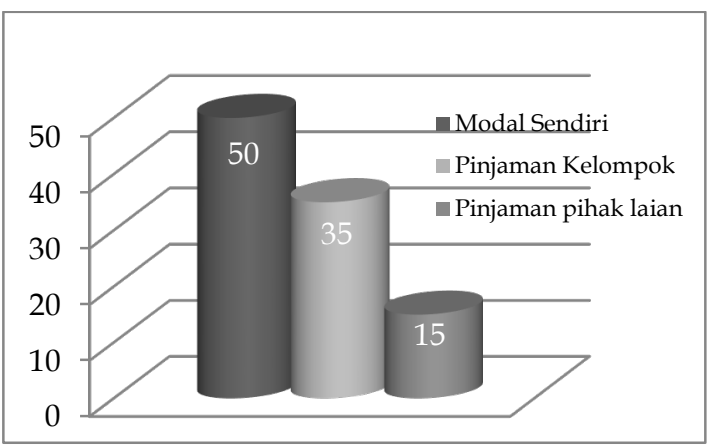

Gambar 2. Sumber Kepemilikan Modal Sumber : Hasil Olahan Data Primer, 2020

\section{KELAYAKAN SOSIAL DAN LINGKUNGAN}

Aspek sosial dan lingkungan yang dirasakan petani dengan adanya usahatani Labu Madu membuka lapangan pekerjaan bagi masyarakat sekitar seperti buruh tani, pedagang dan sarana wisata agro sentra Labu Madu berangsur-angsur membaik. Ada dua lokasi Sentra Labu Madu yang dirintis sebagai Wisata Agro di Kabupaten Pandeglang dan pengunjung dapat memanen sendiri buah Labu Madu langsung dari pohonnya. Ada dua lokasi Agro wisata yang dikembangkan di pandeglang yang dikelola oleh Gematani pimpinan H Mulyadi R. SE dengan luas 1,5 Ha. Tingkat keamanan wilayah dalam hal ini pencurian buah Labu Madu cukup baik artinya hanya sedikit kasus yang ditemukan dan umumnya hanya dilakukan untuk meme- nuhi kebutuhan sendiri sehingga tidak membahayakan kepada petani Labu Madu.

Pengolahan limbah budidaya labu madu tidak banyak mengalami kendala, umumnya limbah batang labu madu setelah panen diolah kembali sebagai bahan pupuk organik, selain itu hampir semua petani dilokasi penelitian telah memanfaatkan mulsa plastik dalam membudidayakan labu madu sehingga pertumbuhan gulma dapat ditekan.

Secara sosial dan ekonomi budidaya Labu Madu memberikan manfaat yang tinggi bagi petani dan lingkungan sekitar, diaman dalam 0,25 Ha petani memanfaatkan tenaga kerja antara 3-4 orang, karenanya perekonomian di lokasi penelitian lebih bergeliat. Kenaikan harga-harga sembako berimbas pada berkurangnya alokasi modal usahatani Labu Madu, karena umumnya petani mencampur pengeluaran rumah tangga dengan pengeluaran usahataninya.

Gambar 3 menunjukkan bahwa 65\% petani beranggapan kenaikan harga sembako mempengaruhi dalam usahataninya, sedangkan 35\% tidak merasa berpengaruh dikarenakan skala usahataninya tidak besar.

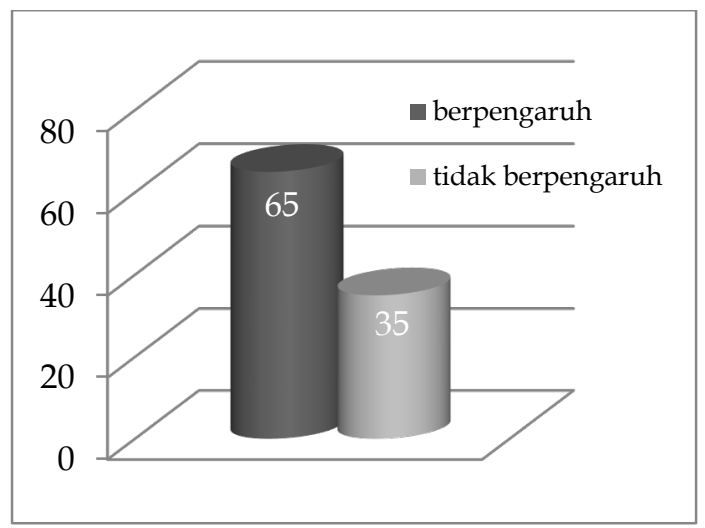

\section{Gambar 3. Pengaruh Kenaikan Biaya Usahatani \\ Sumber : Hasil Olahan Data Primer, 2020}

\section{SALURAN PEMASARAN LABU MADU}

Saluran pemasaran Labu Madu di Kecamatan Cipeucang dan Cimanuk pada umumnya petani yang membudidayakan Labu Madu ialah perseorangan tidak tergabung dalam kelompok tani, sehingga 


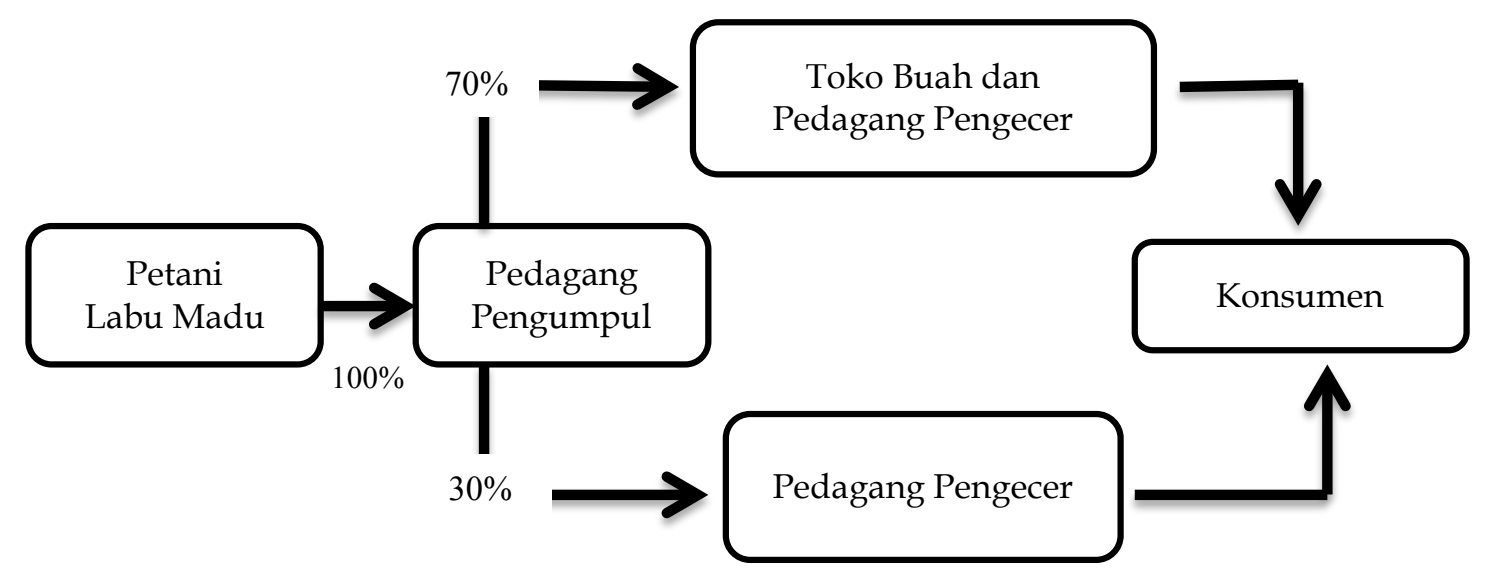

Gambar 4. Saluran Pemasaran Buah Labu Madu di Pandeglang

hasil panennya dijual semua kepada pedagang besar.

Gambar 4, menjelaskan bahwa Labu Madu memiliki 2 saluran. Saluran pertama dari petani $100 \%$ hasil dijual ke pedagang pengumpul, dari pedagang pengumpul $30 \%$ Labu Madu dijual kepada pedagang pengecer dan $70 \%$ Labu Madu dijual kepada agen buah yang lalu dijual kembali ke konsumen terakhir.

\section{KESIMPULAN DAN SARAN}

\section{KESIMPULAN}

Berdasarkan hasil pembahasan yang telah dijelaskan maka dapat disimpulkan sebagai berikut :

1. Bahwa Analisis Kelayakan pada proyek budidaya Labu Madu di Kecamatan Cipeucang dan Cimanuk Kabupaten Pandeglang dilihat dari 4 elemen utama kriteria kelayakan yaitu Net Present Value (NPV)), dan Internal rate Of return (IRR). Berdasarkan hasil perhitungan yang didasari oleh arus kas, maka proyek ini dapat dikatakan layak untuk direalisasikan, hal ini terlihat dari pertimbangan kelayakan proyek yang dapat dilaksanakan dilihat dari kriteria kelayakan yang dihasilkan yakni:

a. Ratio BC diperoleh sebecar 1,43 lebih besar dari 1

b. Net Present Value (NPV) bernilai positif sebesar Rp 44.658.301,28 c. Internal Rate of Return (IRR) sebesar $=$ $27,24 \%$ menunjukkan tingkat kembalian lebih beasr dari tingkat suku bunga

d. Payback period (PBP) selama 0,59 atau selama enam bulan (lebih dari) satu musim.

2. Hasil analisis sensitivitas (switching value) menunjukkan bahwa Penurunan Produksi sebesar 10\% lebih peka atau sensitif jika dibandingkan dengan penurunan harga jual dan kenaikan biaya produksi dalam usahatani labu madu, aspek ekonomi lingkungan sosial dan pemasaran labu madu di Kecamatan Cipucang dan Cimanuk Pandeglang masih terbuka untuk dikembangkan.

\section{SARAN}

1. Usahatani labu madu dapat dijadikan sebagai usahatani yang utama karena di Kecamatan Cipeucang, dan Cimanuk Kabupaten Pandeglang selain harga jual yang baik juga memberikan peningkatan pendapatan yang tinggi.

2. Bagi Petani labu madu di Kecamatan Cipeucang, dan Kecamatan Cimanuk Kabupaten Pandeglang diharapkan dapat meningkatkan produktivitasnya dengan meningkatkan nilai input dengan selalu memperhatikan nilai BC, IRR maupun NPV yang masih sangat terbuka untuk ditingkatkan. 


\section{DAFTAR PUSTAKA}

Ardana, K.B., Pramudya, M.H. dan Tambunan, A.H. 2008. Pengembangan tanaman jarak pagar (Jatropha Curcas L) mendukung kawasan mandiri energi di Nusa Penida, Bali. Jurnal Littri 14 (4) : 155161.

Arikunto S. 2002. Prosedur Penelitian Suatu Pendekatan Praktek. Rineka Cipta. Jakarta.

Astanu DA. 2013. Analisis Kelayakan Finansial Budidaya Intensif Tanaman Pala di Kecamatan Gisting Kabupaten Tanggamus. JIIA Vol 1: No 3 : 1-8.

[BPS] Badan Pusat Statistik 2008. Produktivitas, produsi dan luas panen jagung. $\quad \mathrm{http} / /$ : bps.go.id/sector/jagung/table1. shtml. [11 Mei 2008].

[BPS] Badan Pusat Statistik Kabupaten Pandeglang. 2017. Pandeglang dalam Angka. Pandeglang.

[BPS] Badan Pusat Statistik Provinsi Banten 2014. Banten Dalam Angka. Banten.

[BPS] Badan Pusat Statistik Provinsi Banten 2017. Banten Dalam Angka. Banten.

Bank Indonesia. 2019. Angka Inflansi Tahun 2019. Jakarta.

Blank, L. dan Anthony, T. 2002. Engineering Economy,5thed. Mc.Graw Hill, New York.

De Garmo,E.E., Paul, W.G., Sullivan dan Canada, J.R. 1984. Engineering Economic, 7thed. Mac MillanPub.Co, New York.

Diatin, I., Sobari, M.P. dan Irianni, R. 2007. Analisis kelayakan finansial budidaya ikan nila wanayasa pada kelompok pembudidaya mekarsari. Jurnal Akuakultur Indonesia 6(1): 97-102.

Dinas Pertanian Tanaman Pangan dan Hortikultura 2018. Data Produksi Hortikultura Pandeglang. Provinsi Banten.
Erlina 2006. Analisis perancangan agroindustri berbasis karet. Jurnal Bisnis dan Manajemen 3(1):73-92.

Fazwa, M.A.F., Fauzi, P.A., Ab, A.G., Rasip dan Noor, M.M. 2001. A preliminary analysis on financial assessment of Citrushystrix (limau purut) grown on plantation basis, Forest Research Institute Malaysia (FRIM), 52109 Kepong, Selangor Darul Ehsan, Project No. 01- 0401-0094-EA001.

Firmansyah, B.A., Veronika, A. dan Trigunarsyah, B. 2006. Risk Analysis in feasibility study of building construction project: case study- PT. Perusahaan Gas Negara Indonesia. The Tenth East AsiaPacific Conference on Structural Engineering and Construction, Bangkok, Thailand Tahun 2006. Bangkok 3-5 Agustus, Thailand.

Gittinger JP dan Hans AA. 1993. Evaluasi Proyek. Jakarta.

Idham, A., Lestari, T. dan Adriani, D. 2010. Analisis finansial sistem usaha tani terpadu (integrated farming system) berbasis ternak sapi di kabupaten oganilir. Jurnal Pembangunan Manusia 6. http:// balitbangdasumsel.net/data/do wnload/ 20100414125413.pdf. [3 April 2011].

Kadariah. 2001. Evaluasi Proyek Analisa Ekonomi. Lembaga Penerbit Fakultas Ekonomi. Universitas Indonesia. Jakarta.

Kusuma, P.T.W.W., Arbita, K.D., Putri, S.A. dan Maryani, N.F. 2010. Financial analysis pengembangan usaha kecil menengah (UKM) produsen flakes ubi jalar (emergency food) (studi kasus UKM mandiri pangan mapan makmur, Gunung Kidul). Seminar on Application and Research in Industrial Technology 2010 (SMART): C1-C6. Yogyakarta, 29 Juli 2010 : Universitas Gadjah Mada Yogyakarta.

Kusumanto, I. 2008. Net present value (NPV) internal dan rate of return (IRR). http://kuliahft. umm.ac.id/ pluginfile.php/171/ mod_folder/ content/1/Ekonomi\%20Teknik/5.\%20N 
PV\%20IRR. ppt?forcedownload $=1 . \quad[28$ Agustus 2013].

Logistik Bimbingan Pupuk Dan Pemupukan Indonesia. 2016. Acuan pupuk dan pemupukan labu madu/butternutsquash.

http://booslem.com/ budi dayabutternut-labu-madu/. Diunduh September 2018

Mc Keough, P., Solantausta, Y., Kyll`nen, H., Faaij, A., Hamelinck, C., Wagener, M., Beckman, D. dan Kjellstrom, B. 2005. Techno-economic analysis of biotradechains. Upgraded Biofuels from Russia and Canada to the Netherlands Espoo 2005. Research VTT Tiedotteita. Research Notes 2312. pp. 25.

Pujawan, I.N.(2004). Ekonomi Teknik. Penerbit Guna Widya, Surabaya.

Rantala, J., Harstela, V.M., Saarinen dan Tervo, L. 2009. ATechno-Economic Evaluation of Bracke and M-PlanterTree Planting Devices. Research Article the Finnish Society of Forest Science ISSN 0037-5330. The Finnish Forest Research Institute Silva Fennica: p 43(4).

Redaksi24.Com 2019. Agrowisata alam Pandeglang, b Koran Online

Rizana, D. 2014. Analisis Penentuan Harga Pokok Produksi dan Kelayakan Finansial Pepaya Kalifornia di Kabupaten Pandeglang. JIIA Vol 2: No 3 : 1-9.

Seftiana, L. 2010. Analisis Kelayakan Usahatani Pepaya di Desa Blendung, Kecamatan Purwadadi Kabupaten Subang. JMA IPB Vol 3 : No 2 : 1-6.

Sudong, Y. dan Tiong, R.L.K. 2002. NPV-at risk method in infrastructure project investment evaluation. Journal of Construction Engineering and Management 126(3): 227-233.

Surahman, D.N., Astro, H.M. dan Priyatna, H. 2007. Business Plan: Kajian Bisnis Agroindustri, Studi Kasus Usaha Kecil Menengah Nanas. LIPI Press, Jakarta.
Sutojo, S. (2000). Studi Kelayakan Proyek, Teori dan Praktek. Gramedia, Jakarta. 